\title{
Results of Belgian quality control framework for cavity wall insulation
}

\begin{abstract}
Since 2012 a quality control system is in operation in Belgium to provide confidence in the quality of the works of cavity wall insulation in existing walls. When the works are in line with the quality framework, the installer may provide a declaration of conformity to the client, which he can use to receive subsidies or for energy performance certification.

A field study was performed to analyze the relationship between the information provided by installers in the declaration of conformity, the results of the conformity checks performed by the certification organization and the effective cavity wall performance measured on site.
\end{abstract}

Ergebnisse der Belgischen Qualitätskontrolle für die nachträgliche Wärmedämmung von Hohlwänden. Seit 2012 ist in Belgien ein System zur Qualitätskontrolle in Betrieb, das Vertrauen in die nachträgliche Wärmedämmung bestehender Wände schaffen soll. Wenn die Arbeiten im Einklang mit dem Qualitätsrahmen erbracht wurden, kann der Ausführungsbetrieb dem Kunden eine Konformitätserklärung ausstellen, die dieser für die Zuteilung von Zuschüssen und für die Ausstellung eines Energieausweises nutzen kann. Es wurde eine Feldstudie durchgeführt, um die Angaben in den Konformitätserklärungen der Ausführungsbetriebe mit den Ergebnissen der Konformitätsprüfung durch die Zertifizierungsgesellschaft und mit den vor Ort gemessenen effektiven Dämmwerten zu vergleichen.

\section{Introduction}

The mass market application of cavity wall insulation in existing walls is an important measure to achieve a reduction of the energy use and greenhouse gas emissions related to heating the existing Belgian housing stock. Approximately $25 \%$ of the existing Flemish housing stock still has non-insulated cavity walls today $\left(\mathrm{U} \approx 1.5 \mathrm{~W} /\left(\mathrm{m}^{2} \mathrm{~K}\right)\right)$, with cavity widths larger than $50 \mathrm{~mm}$ in more than $80 \%$ of the houses.

Since 2012 a quality control system is in operation in Belgium to provide confidence in the quality of the works of cavity wall insulation in existing cavity walls. This technique allows to insulate existing cavity walls by blowing or pumping insulation product into the empty cavity through pre-drilled holes in the outer or inner masonry leaf.

Existing cavity walls are considered suitable for correct installation of thermal insulation on following conditions: (1) the minimum cavity width is $50 \mathrm{~mm},(2)$ the façade and wall are in good condition, with no sign of damage or cracks, (3) the driving rain load is limited - façade height should typically be lower than $8 \mathrm{~m}$, (4) the indoor moisture load is limited according to STS standard [1].

For cavity wall insulation to perform correctly, three criteria must be met: (1) the building must be inspected and shown to be suitable, (2) the insulation system must have been tested and shown to meet a number of criteria and (3) trained technicians must carry out the installation to a high standard [1], [2].

When the works are performed according to these criteria, the installer may provide a declaration of conformity to the client. In the Flemish region in Belgium the authorities subsidize the installation of cavity wall insulation in existing walls on the condition that a declaration of conformity is presented by the building owner. Furthermore, if the installation of insulation is part of a major renovation for which energy performance requirements apply, the retrofitted cavity wall should have a declaration of conformity and achieve a U-value not higher than $0.55 \mathrm{~W} /\left[\mathrm{m}^{2} \mathrm{~K}\right]$.

The whole system is managed by a quality control and certification organization which is responsible for the assessment and approval of products and systems, the training of installers, and the conformity checks on building sites. The Belgian technical approval authority in construction (UBAtc) and the Belgian construction certification association (BCCA) take up this role. Typically over 1500 installations per month are executed within the system (on a market of 600.000 houses with non-insulated cavity walls) [9].

The reported cavity width is an important element in deciding whether the cavity may be filled with insulation product, and in defining the U-value of the wall in EPCreports. Therefore the installer should measure the cavity width at least at one point per façade during inspection, and at least once every $10 \mathrm{~m}^{2}$ façade surface during installation, with a minimum of 3 measurements for each façade.

Previous studies showed that the quality of installation of cavity wall insulation might be a concern. For example, a field study was carried out in the UK to determine the as built thermal performance of a sample of $70 \mathrm{dwel}$ lings during 2005 and 2006 based on in-situ U-value measurements [3]. The study showed that the actual realised improvements to U-values were in many cases less than would be expected on the basis of calculating U-values. The improvement in thermal resistance was, on average, 
$38 \%$ less than that which would be expected on the basis of measured cavity widths.

Since the quality control system in Belgium has been operational for a relatively small time span, and the conformity checks are performed on a small sample of all installations, it is unclear whether the system effectively meets the objectives of improving the quality of the works. Therefore a field study was performed to analyze the relationship between the information provided by the installers in the declaration of conformity, the results of the conformity checks performed by the certification organization and the effective cavity wall performance on site.

The analysis of the field study is focusing on both the compliance of input data and the quality of the works by confronting the different sources of information:

- Compliance of input data: to what extent is the information provided by installers conforming with specifications (wall area, cavity width,...).

- Quality of the works: relation between measured U-values and theoretical U-value based on reported cavity width and insulation product data.

\section{Methods}

The study is based on the field investigation of 26 detached and semi-detached houses, built between 1900 and 1995, with retrofit cavity wall insulation installed in 2012 or 2013 under the quality control framework. The field measurements were performed in winter 2014. The projects were selected in collaboration with BCCA, the organization responsible for the independent audits of certified materials and installers. The selected case studies in the sample were scattered over Flanders, to get representative results. Next to that, the case studies can be split according to two parameters: type of insulation product and conformity after installation; which is shown in Table 1 .

Three insulation products are considered, as these are the only products with technical approval used on the Belgian market: loose-fill glass wool (MW), EPS-beads and PUR-foam (for this application typically of the open cellular type). More than half of the houses in the sample were checked by the certification organization and have an auditing report available. During an audit on site the assessor checks whether the technical guidelines for inspection and product installation are correctly followed, and takes material samples for further analysis of product properties. It was also decided to include a number of projects for which the declaration of conformity was not granted due to noncompliance to one of the installation guidelines. Typical non-conformities are of a procedural nature, e.g. incorrect registration of tests of the installation equipment prior to installation.

The share of assessed and non-compliant projects in the sample is not representative for the amount of projects which are checked in practice or for the amount of projects that are non-compliant. These cases were included in the sample to be able to investigate whether the occurrence of independent assessments, or the occurrence of non-conformities had an influence on the performance of the insulated cavity walls.
Table 1. Number of cases included in each control group Tabelle 1. Anzahl der Fälle in jeder Kontrollgruppe

\begin{tabular}{|l|l|l|l|}
\hline & $\begin{array}{l}\text { Check BCCA } \\
\text { Compliant } \\
\text { (CC) }\end{array}$ & $\begin{array}{l}\text { Check BCCA } \\
\text { Non-compliant } \\
\text { (CNC) }\end{array}$ & $\begin{array}{l}\text { Not checked } \\
\text { by BCCA } \\
\text { (NC) }\end{array}$ \\
\hline MW & 3 & 2 & 4 \\
\hline EPS & 3 & 2 & 3 \\
\hline PUR & 3 & 2 & 4 \\
\hline
\end{tabular}

For each case study information was collected from the certification organization and the owners, to allow for an accurate estimation of the U-value of the walls, and for an assessment of the correctness of input data provided by the installers. The following information was used for further analysis:

- the declared thermal conductivity of the insulation product $\lambda_{\mathrm{D}}$, available in the technical approval document,

- cavity width $\mathrm{d}$, provided in the inspection and installation reports by the installers (in 12 out of 26 projects the installer only reported a single value, contrary to specifications),

- results of conformity checks, provided in auditing reports by the independent assessor,

- wall composition, derived from analysis of architectural drawings and from observation on site.

\section{$2.1 \mathrm{U}$-value calculation}

For each project the collected information was used to estimate the wall U-value. The correctness of data provided by the installers as well as the quality of the works was assessed based on the comparison between the U-value measured on site and the calculated U-values.

The design value of a retrofit insulated cavity wall is calculated according to section 7.2 of STS 71-1 [1]. This method is also included in the specifications for defining transmission characteristics in the framework of energy performance regulations [4], which are in force if the installation of insulation is part of a major renovation for which energy performance requirements apply (this was not the case for the projects in this study).

The thermal performance of cavity walls is expressed as the corrected heat transfer coefficient $\mathrm{U}_{\mathrm{c}}\left(\mathrm{W} / \mathrm{m}^{2} \mathrm{~K}\right)$, using Eqs. (1), (2).

$\mathrm{U}_{\mathrm{c}}=1 / \mathrm{R}_{\mathrm{T}}+\Delta \mathrm{U}_{\mathrm{cor}}+\Delta \mathrm{U}_{\mathrm{f}}$

$\Delta \mathrm{U}_{\text {cor }}=1 /\left(\mathrm{R}_{\mathrm{T}}-\mathrm{R}_{\text {cor }}\right)-1 / \mathrm{R}_{\mathrm{T}}$

$\mathrm{R}_{\mathrm{T}} \quad$ total thermal resistance of wall $\left[\left(\mathrm{m}^{2} \mathrm{~K}\right) / \mathrm{W}\right]$

$\Delta \mathrm{U}_{\text {cor }}$ correction factor that takes into account a reduction $\mathrm{R}_{\text {cor }}$ of the total thermal resistance $\mathrm{R}_{\text {cor }}=0.2\left(\mathrm{~m}^{2} \mathrm{~K}\right) / \mathrm{W}$, and takes into account the uncertainties due to imperfections of the installation $\left[\mathrm{W} /\left(\mathrm{m}^{2} \mathrm{~K}\right)\right]$;

$\Delta \mathrm{U}_{\mathrm{f}} \quad$ correction factor for mechanical fixings (wall ties) through the insulation layer $\left[\mathrm{W} /\left(\mathrm{m}^{2} \mathrm{~K}\right)\right]$ 
If no declared thermal conductivity is available for one of the material layers, default values are given in Appendix A of the specifications [4] These values were used for all the material layers, except for the insulation layer. The thermal resistance of the insulation layer was calculated using the declared thermal conductivity provided by the manufacturer.

Several sources of uncertainty exist in the definition of the U-value of an insulated existing cavity wall: cavity width, wall composition and thermal properties of material layers, imperfections of installation... The uncertainty interval is estimated based on the value $\mathrm{R}_{\mathrm{cor}}$ of $0.2\left(\mathrm{~m}^{2} \mathrm{~K}\right) / \mathrm{W}$. A calculation example is given in Table 2 .

\subsection{Field measurements}

For each case-study, a heat flow meter measurement was made during winter 2014, measuring the heat-flux on the inside wall surface and the surface-temperature on both sides of the wall. The measuring equipment was installed at two adjacent locations. Positioning of the sensors was optimized based on thermography to make sure that the measurements were not disturbed by local thermal bridging [5]. Each measurement period lasted at least 5 days up to 12 days, with measurement intervals smaller than 1 minute for the sensors on the inside surface and smaller than 5 minutes for the temperature sensor on the outside.

The measurement data was analysed with both the average methods and the dynamic method in accordance to ISO 9869 [6], [8]. The average method is based on the simple relationship between steady-state heat-flux, temperature difference across the wall and thermal resistance of the wall. Eq.(3) gives the estimate of the average method of the surface to surface heat resistance after $\mathrm{N}$ measurements. The U-value is estimated by adding the theoretical values of surface resistances $R_{s i}$ and $R_{\text {se }}$ to the estimated surface to surface resistance and inverting this sum, with $\mathrm{R}_{\mathrm{si}}=0.13 \mathrm{~m}^{2} \mathrm{~K} / \mathrm{W}$ and $\mathrm{R}_{\mathrm{se}}=0.04 \mathrm{~m}^{2} \mathrm{~K} / \mathrm{W}$.

$$
\mathrm{R}_{\mathrm{N}, \mathrm{s}-\mathrm{to}-\mathrm{s}}=\frac{\sum_{\mathrm{k}=1}^{\mathrm{N}}\left(\mathrm{T}_{\mathrm{i}, \mathrm{s}, \mathrm{k}}-\mathrm{T}_{\mathrm{o}, \mathrm{s}, \mathrm{k}}\right)}{\sum_{\mathrm{k}=1}^{\mathrm{N}} \mathrm{q}_{\mathrm{i}, \mathrm{s}, \mathrm{k}}}
$$

where

$\mathrm{R}_{\mathrm{N} \text {,s-to-s }}$ surface-to-surface thermal resistance $\left[\mathrm{m}^{2} \mathrm{~K} / \mathrm{W}\right]$

$\mathrm{k}$ time series of individual measurement

$\mathrm{T}_{\mathrm{i}, \mathrm{s}, \mathrm{k}} \quad$ inside surface temperature [K]

$\mathrm{T}_{\mathrm{o}, \mathrm{s}, \mathrm{k}} \quad$ outside surface temperature $[\mathrm{K}]$

$\mathrm{q}_{\mathrm{i}, \mathrm{s}, \mathrm{k}} \quad$ inside surface heat flux $\left[\mathrm{W} / \mathrm{m}^{2}\right]$.

Because of the dynamic boundary conditions in-situ, the measured values are averaged over a large amount of time, of at least 3 days. Taking into account the prominent daily cycles of the boundary conditions, the end-result is calculated after a round number of 24 hours. A number of conditions have to be met in order to obtain reliable results, eg the estimate at the end of the test period should not deviate by more than $5 \%$ from the estimate at 24 hours before. For most of the cases, the neces-
Table 2. U-value calculation for case $1.1-M W$ Tabelle 2. U-Wert-Berechnung für Fall 1.1 - Glaswolle

\begin{tabular}{|l|l|l|l|l|}
\hline & $\mathrm{d}[\mathrm{m}]$ & $\lambda[\mathrm{W} / \mathrm{mK}]$ & $\mathrm{R}\left[\mathrm{m}^{2} \mathrm{~K} / \mathrm{W}\right]$ & $\mathrm{U}\left[\mathrm{W} / \mathrm{m}^{2} \mathrm{~K}\right]$ \\
\hline $\mathrm{R}_{\mathrm{si}}$ & - & - & 0.13 & - \\
\hline $\begin{array}{l}\text { Gypsum } \\
\text { plaster }\end{array}$ & 0.01 & 0.52 & 0.019 & - \\
\hline $\begin{array}{l}\text { Perforated } \\
\text { brick }\end{array}$ & 0.14 & 0.334 & 0.420 & - \\
\hline $\mathrm{MW}$ & 0.07 & 0.034 & 2.059 & - \\
\hline Brick & 0.09 & 1.61 & 0.056 & - \\
\hline $\mathrm{R}_{\mathrm{se}}$ & - & - & 0.04 & - \\
\hline$\Sigma$ & 0.31 & - & 2.724 & 0.37 \\
\hline$\Delta \mathrm{U}_{\mathrm{f}}$ & - & - & - & 0.02 \\
\hline$\Delta \mathrm{U}_{\text {cor }}$ & - & - & - & 0.03 \\
\hline $\mathrm{U}_{\mathrm{c}}$ & - & - & - & $\begin{array}{l}0.42 \\
{[0.38-0.45]}\end{array}$ \\
\hline
\end{tabular}

sary convergence criteria were only met after at least 5 days.

This summation over time might not always be enough to compensate for the variations in inside and outside temperature, depending on the thermal capacity of the wall. Therefore, "storage correction" factors are proposed in the norm, based on estimations of the thermal properties of the wall. In the framework of this research, the average method was always applied both with and without storage correction factors, even when it was not necessary according to the norm.

The other method described in the norm, the dynamic analysis method, was also applied on all measurements. This approach is built on a set of linear equations to be solved in order to find the time-based relationship between the temperature variations on both sides of the wall and the measured heat flux. The accuracy of the defined variables is tested by comparing the measured values of the heat-flux over time to an estimate, calculated with these variables. With this more complex method, the thermal transmittance of the wall can often be determined after a smaller measurement period. For each set of data, the dynamic analysis was applied repeatedly with 1 to 8 time constants, selecting afterwards the result with the smallest confidence interval. Further individual analysis of each measurement, mainly through visual analysis of the charts appeared to be crucial for reaching the best results.

The application of the different data analysis methods results in three different U-values. Also the measuring uncertainty depends on the analysis method chosen. The measuring uncertainty was estimated for each individual measurement and method according to the norm, taking into account uncertainties related to measuring accuracy, installation and operational errors, and to the data analysis method and the way it copes with signal variations. To estimate total uncertainty the quadrature sum of contributing errors was taken.

As an example, Table 3 shows all resulting estimates for case 1.1. The example illustrates how the storage correction factors help to obtain reliable results with the average method: for sensor 1 the convergence criteria were not met when no storage correction was applied. For this ex- 
Table 3. U-value estimates for case $1.1-M W$ based on heat flow meter measurements

Tabelle 3. U-Wert-Schätzungen für Fall 1.1 - Glaswolle, nach Messungen des Wärmeflusses

\begin{tabular}{|l|l|l|l|l|}
\hline \multicolumn{3}{|l|}{ Sensor 1 } & \multicolumn{2}{l|}{ Sensor 2 } \\
\hline $\begin{array}{l}\text { ISO 9869 } \\
\text { method }\end{array}$ & $\begin{array}{l}\text { U-value } \\
{[\mathrm{W} /} \\
\left.\left(\mathrm{m}^{2} \mathrm{~K}\right)\right]\end{array}$ & $\begin{array}{l}\text { Uncer- } \\
\text { tainty }\end{array}$ & $\begin{array}{l}\text { U-value } \\
{\left[\mathrm{W} /\left(\mathrm{m}^{2} \mathrm{~K}\right)\right]}\end{array}$ & $\begin{array}{l}\text { Uncer- } \\
\text { tainty }\end{array}$ \\
\hline Method $\left.1^{*}\right)$ & \multicolumn{2}{|l|}{ No convergence } & 0.49 & $9 \%$ \\
\hline Method 2*) & 0.40 & $10 \%$ & 0.48 & $9 \%$ \\
\hline Method $\left.3^{*}\right)$ & 0.44 & $12 \%$ & 0.45 & $12 \%$ \\
\hline
\end{tabular}

*) Method 1 = average method without storage correction; Method $2=$ average method with storage correction; Method $3=$ dynamic method

ample the results of the average method with storage correction are consistent with the results of the dynamic analysis method: the values of one method fall within the confidence intervals of the other method. Compared to the theoretical value for this wall, presented in Table 2, the measured values show good agreement, except for the estimate obtained for sensor 2 using the average method, which falls outside the theoretical confidence interval of $0.38-0.45 \mathrm{~W} /\left(\mathrm{m}^{2} \mathrm{~K}\right)$.

However, contrary to the example, not in all cases the results of the different analysis methods were consistent. In a large number of measurements the estimates based on the dynamic analysis method showed large uncertainties (>20\%), with sometimes physically unrealistic values. For this reason it was decided to use only the estimated Uvalues based on the average method with storage correction, and to reject the results in cases where the convergence criteria for this method were not met. Finally this resulted in reliable U-value estimates for 21 out of 26 cases, with maximum uncertainty of $10 \%$. In the cases with reliable U-value estimates, the mean value of the two sensors was used as the final result. In cases where a reliable estimate was only obtained with one of the sensors, this single value was used as the final result (4 cases).

Of course the heat flow measurements are local measurements and give an estimate of the thermal performance of the wall at a single position. To complement these measurements and provide information on the continuity and homogeneity of thermal insulation all case studies were subjected to thermographic investigations [5], [8]. These investigations showed a good continuity of the insulation product in all case studies, except in 3 EPS-projects where indications of local gaps or inhomogeneity of the insulation layer were observed.

\section{Results}

The quality of the works as well as the correctness of data provided by the installers is assessed based on the comparison between the U-value measured on site and the calculated $\mathrm{U}_{\mathrm{c}}$-values. Figure 1 shows the relationship between both sets of U-values. Each symbol represents a case study, with indication of insulation products. The dashed lines represent the confidence interval taking into account the measuring uncertainty and uncertainties in calculation. As described in the previous sections the uncertainty in calcu-

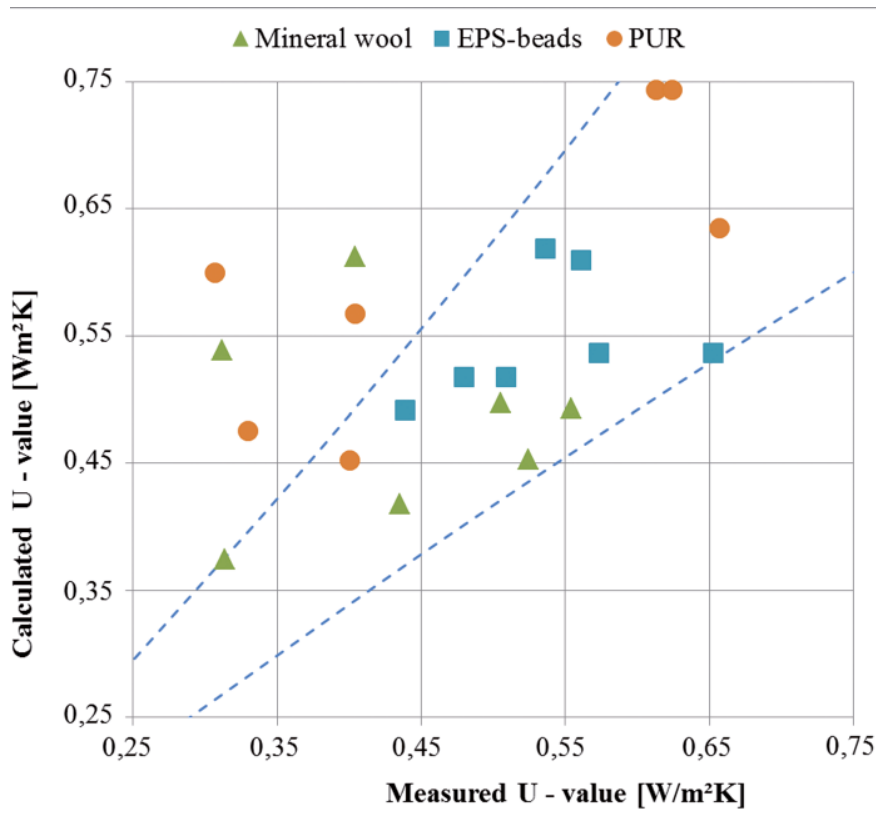

Fig. 1. Comparison between measured and calculated $U$-values in the case-studies (dashed lines represent the confidence interval taking into account $10 \%$ measuring uncertainty and an uncertainty $R_{\text {cor }}=0.2 \mathrm{~m}^{2} \mathrm{~K} / \mathrm{W}$ in the calculated U-value)

Bild 1. Vergleich gemessener und berechneter U-Werte in den Fallstudien (gestrichelte Linien zeigen das Konfidenzintervall unter Berücksichtigung von $10 \%$ Messunsicherheit sowie Unsicherheit $R_{\text {cor }}=0,2 \mathrm{~m}^{2} \mathrm{~K} / \mathrm{W}$ beim berechneten $U$-Wert)

lation is estimated based on the value $R_{\text {cor }}=0.2 \mathrm{~m}^{2} \mathrm{~K} / \mathrm{W}$, and the maximum measuring uncertainty is $10 \%$. In $33 \%$ of the cases the measured U-value is higher than the calculated value (poorer thermal performance in reality), while the opposite is true in $67 \%$ of the cases (better thermal performance in reality).

However, when the confidence interval is taken into account, in none of the cases the measured U-value is significantly higher than the theoretical value. This means that the thermal performance of cavity wall insulation meets the expectations in all of the studied houses. The lack of continuity or homogeneity in insulation fill observed in thermography's of three EPS-projects does not lead to poor measured U-values. In 5 out of 21 cases there is a significant deviation between measured and calculated values, but here the walls seem to perform better than expected. Possible reason is that the reported mean cavity width is incorrect or small compared to the local cavity width where the measurements were taken. Another possible reason is that the wall composition used for calculation is incorrect. In 2 of these cases there was a gypsum board internal lining, perhaps hiding a layer not taken into account in the calculation.

To analyse differences between the control groups in the field study, the measured U-values are further analysed in relation to the insulation product and to the results of conformity checks. In this analysis the 2 cases with gypsum board internal lining are not considered since the previous analysis indicated the wall composition may differ from that of a typical cavity wall. 


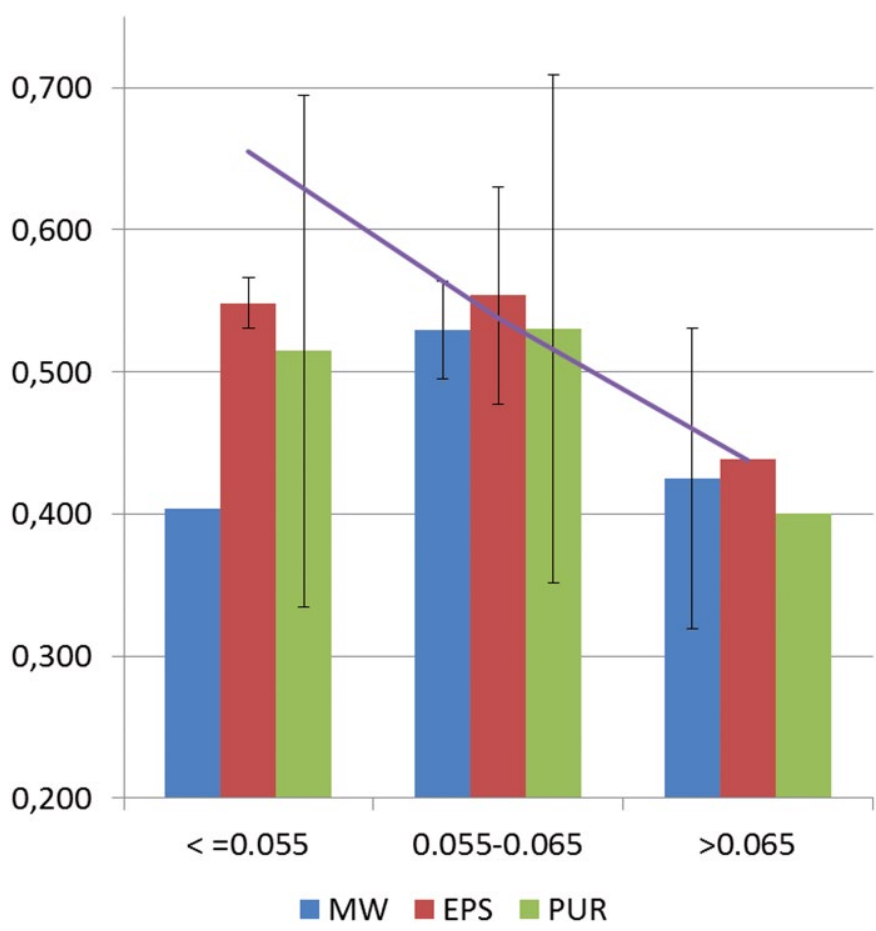

Fig. 2. U-value $\left[W /\left(m^{2} K\right)\right]$ as a function of insulation product and cavity width [m]: mean measured values (bars) versus mean theoretical values $U_{c}$ (line)

Bild 2. U-Wert $\left[W /\left(m^{2} K\right)\right]$ als Funktion des Dämmmaterials und der Hohlraumbreite [m]: gemessene Mittelwerte (Balken) im Vergleich zu theoretischen Mittelwerten $U_{c}$ (Linie)

Figure 2 shows the measured U-values as a function of cavity width and insulation product. The projects are subdivided in 3 groups according to the reported cavity width:

- $50 \mathrm{~mm} \leq \mathrm{d} \leq 55 \mathrm{~mm}$

- $55 \mathrm{~mm}<\mathrm{d} \leq 65 \mathrm{~mm}$

- $65 \mathrm{~mm}<\mathrm{d} \leq 70 \mathrm{~mm}$

The bars in Fig. 2 represent the mean measured values in each group, with the error bars indicating the standard deviation. When no error bar is drawn, there is only a single measured value in the group. These measured values are compared to the mean theoretical value $U_{c}$ in each group, represented by the line in the graph. The mean measured values vary between 0.40 and $0.55 \mathrm{~W} /\left(\mathrm{m}^{2} \mathrm{~K}\right)$, with no significant differences between the three groups of insulation products. Compared to typical U-values of not insulated existing cavity walls [7] the thermal performance of these walls has improved by a factor 3 .

The comparison between mean measured and theoretical values in Fig. 2 shows that there is a good correspondence between both in projects with cavity widths larger than $55 \mathrm{~mm}$. In the group with the narrowest cavities (in between 50 and $55 \mathrm{~mm}$ ) the mean measured values are substantially lower than the theoretical by $16 \%$ (EPS), $21 \%$ (PUR) and $38 \%(\mathrm{MW})$. In fact there is no significant difference between the mean measured values in the group with cavity widths smaller than $55 \mathrm{~mm}$, and the one with cavity widths in between 55 and $65 \mathrm{~mm}$.

Although two of the outliers discussed before are also included in the first group, this is not sufficient to explain the deviation. Perhaps some installers fail to report the

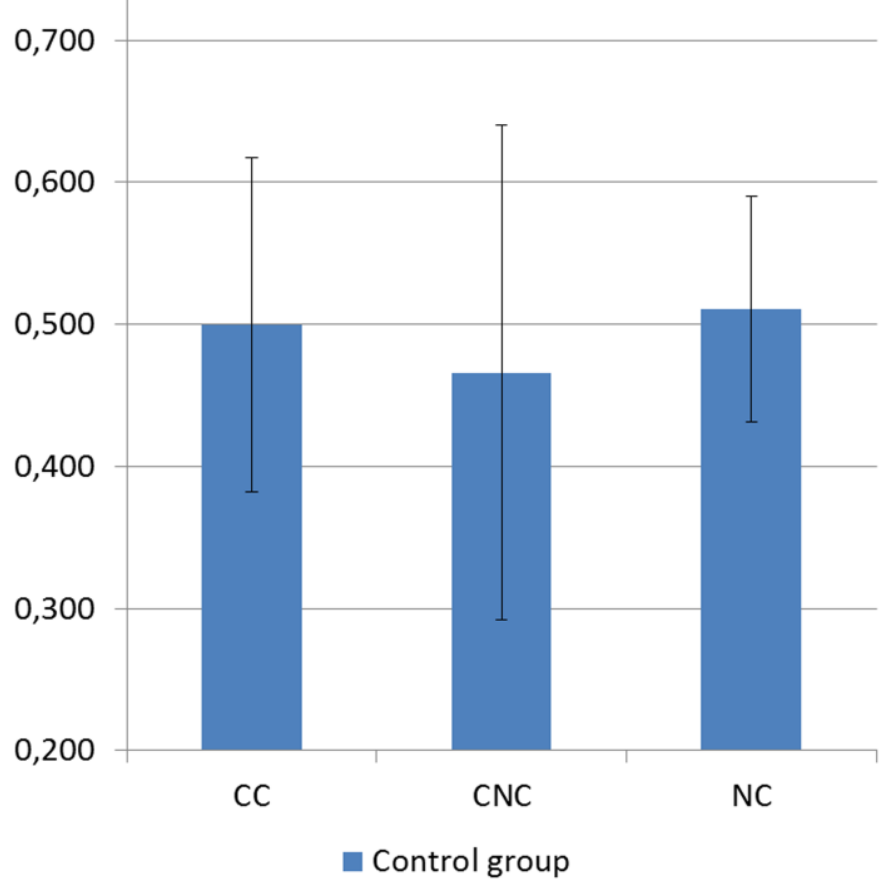

Fig. 3. Mean measured U-value $\left[W /\left(m^{2} \mathrm{~K}\right)\right]$ as a function of results of conformity checks: checked and compliant (CC), checked and not compliant (CNC), not checked (NC) Bild 3. Mittlerer gemessener U-Wert $\left[W /\left(m^{2} K\right)\right]$ in Abhängigkeit von Ergebnissen der Konformitätsprüfungen: als konform geprüft (CC), als nicht konform geprüft (CNC), nicht geprüft (NC)

correct cavity width and simply report the minimum width of $50 \mathrm{~mm}$, which is the necessary condition in the quality control framework for a cavity wall to be suitable for installing insulation. There is certainly no indication that cavity walls with cavity widths smaller than $50 \mathrm{~mm}$ and therefore not suitable for insulation were wrongly assessed by installers to be suitable.

Figure 3 shows the mean measured U-values as a function of the results of conformity checks by independent assessors. For each control group (CC, CNC, NC) the mean and standard deviation of the measured U-values was taken. There is no significant difference between the measured U-values in the control groups. This means that the correct installation of insulation product is maintained also in projects without conformity check, or in projects with non-conformities. Since the established performance does not seem to depend on the occurrence of conformity checks, this is an indication that the full quality chain, such as implemented in Belgium, leads to reliable results. Although conformity checks by independent assessors are performed on a small sample of all installations, this seems to be sufficient to guarantee the effectiveness of the quality control framework for thermal performance.

Although in none of the case studies the installation of insulation was part of a major renovation for which energy performance requirements applied, it is interesting to compare the U-values to the requirement that would be in force in that case: retrofitted cavity walls should achieve a theoretical $\mathrm{U}_{\mathrm{c}}$-value not higher than $0.55 \mathrm{~W} /\left(\mathrm{m}^{2} \mathrm{~K}\right)$. In 16 out of 26 cases $(62 \%)$ the theoretical $\mathrm{U}_{\mathrm{c}}$-value meets this requirement, while in 14 out of 21 cases $(67 \%)$ the mea- 
sured U-value meets the requirement. The 10 cases that are non-compliant $\left(\mathrm{U}_{\mathrm{c}}\right)$ are cases with narrow cavities $(8$ cases with cavity width $\leq 55 \mathrm{~mm}, 2$ cases with cavity width in between 55 and $60 \mathrm{~mm}$ ). In renovation projects for which energy performance requirements apply, the minimum cavity width should thus typically be larger than the minimum suitability requirement of $50 \mathrm{~mm}$ in order to comply to energy performance regulations. The development of insulation products with improved thermal properties could help to meet energy performance requirements even in existing cavity walls with narrow cavities.

\section{Conclusion}

The study is based on the field investigation of 26 detached and semi-detached houses, with retrofit cavity wall insulation installed in 2012 or 2013 under the quality control framework. The analysis of the field study is focusing on both the compliance of input data and the quality of the works by confronting the different sources of information:

- Compliance of input data: to what extent is the information provided by installers conforming with specifications (wall area, cavity width,...).

- Quality of the works: relation between measured U-values estimated from heat flow meter measurements, and theoretical U-values based on reported cavity width and insulation product data.

The study showed that the cavity width of the insulated cavity wall was often not reported correctly by installers and was therefore often not compliant to specifications. In 12 out of 26 cases ( $46 \%$ ) the cavity width was reported as a single value, while multiple measurements should be taken and reported. However, based on the comparison between measured and calculated U-values, there was no evidence that the reported values were wrong. There is also no indication that cavity walls with cavity widths smaller than $50 \mathrm{~mm}$ and therefore not suitable for insulation were wrongly assessed by installers to be suitable.

The study further showed the effectiveness of the quality control framework. The measured U-values vary between 0.31 and $0.66 \mathrm{~W} /\left(\mathrm{m}^{2} \mathrm{~K}\right)$, with no significant differences between the three groups of insulation products studied. In 3 out of 26 cases $(12 \%)$ a thermographic investigation revealed a minor lack of continuity or homogeneity of the insulation product, but this did not result in poor measured U-values. In none of the cases the measured U-value was significantly higher than the theoretical value. This means that the thermal performance of cavity wall insulation meets the expectations in all of the studied houses. The measurements further showed that the correct installation of insulation product was maintained also in projects without conformity check, or in projects with nonconformities. Since the established performance did not seem to depend on the occurrence of conformity checks, this is an indication that the full quality chain, such as implemented in Belgium, leads to reliable results and good quality of the works.
Although in none of the case studies the installation of insulation was part of a major renovation for which energy performance requirements applied, the U-values achieved in the case studies were compared to the requirement that would be in force in that case. The comparison showed that it is difficult to meet the requirement in cavity walls with a cavity width smaller than $60 \mathrm{~mm}$. The development of insulation products with improved thermal properties compared to the approved existing products could help to meet energy performance requirements in existing cavity walls with narrow cavities.

\section{Acknowledgement}

This study was performed in the context of the IEE project QualiChEck (http://qualicheck-platform.eu/). The support is gratefully acknowledged.

\section{References}

[1] STS 71-1 Na-isolatie van spouwmuren door in-situ vullen van de luchtspouw met een nominale breedte van ten minste $50 \mathrm{~mm}$ (in Dutch). Federale overheidsdienst economie, Algemene directie kwaliteit en veiligheid. 2012.

[2] Janssens A., Wagneur, M., Wijnants, J., Winnepenninckx, E.: Na-isolatie van spouwmuren door het opvullen van de luchtspouw (in Dutch). Technische voorlichting 246. Wetenschappelijk en Technisch Centrum voor het Bouwbedrijf. 2012.

[3] Doran, S., Carr, B.: Thermal transmittance of walls of dwellings before and after application of insulation. BRE report $\mathrm{nr}$. 222077. 2008

[4] Transmissiereferentiedocument (TRD), Belgisch staatsblad, 2010 \& 2014 (extension).

[5] NBN EN 13187:1999. Thermal performance of buildings. Qualitative detection of thermal irregularities in building envelopes. Infrared method.

[6] ISO 9869:2014 (E) Thermal insulation - Building elements - In-situ measurement of thermal resistance and thermal transmittance. Part 1: Heat Flow Meter Method.

[7] Delghust, M., Janssens, A., Rummens, J.: Retrofit cavity wall insulation: performance analysis from in-situ measurements. CESBP 2010. Proceedings of the 1st Central European Symposium on Building Physics (D. Gawin, T. Kisilewicz, ed.). Cracow-Lodz, Poland.

[8] Beulque, S.: Uitvoeringskwaliteit van na-isolatie van spouwmuren (in Dutch). Master thesis Ghent University, Department of architecture and urban planning (supervisors A. Janssens and M. Delghust), 2014.

[9] Website http://www.ikisoleermijnspouw.be/ consulted December 2015.

\section{Authors:}

Prof. dr. ir. Arnold Janssens,

Dr. ir.-arch. Marc Delghust,

Prof. dr. ir.-arch. Nathan Van Den Bossche

Ghent University (UGent)

Research Group Building Physics, Construction and Services

Department of Architecture and Urban Planning

Faculty of Engineering and Architecture

Jozef Plateaustraat 22

9000 Gent, Belgium 